\title{
Postnatal Histogenesis of the Adrenal Cortex of the Golden Hamster
}

\author{
By \\ Takashi Ito \\ Department of Anatomy, Nagoya University School of Medicine, Nagoya, Japan \\ (Director: Prof. Ch. Togari)
}

\section{Introduction}

In our laboratory successive studies on the histogenesis and histology of the endocrine glands of laboratory rodents have been made under the direction of Professor Ch. Togari, and it has been found that even in the same genus considerable differences are seen in the structure of the endocrine glands in different species. Therefore, a detailed study of each individual species is necessary for further experimental investigations of these laboratory rodents. Recently the hamster is being utilized as a laboratory animal, and detailed information on the structure of its various organs becomes of great importance. Concerning the adrenal cortex of this animal, some histological and histochemical accounts have been made by Peczenik (1944), Koneff, Simpson and Evans (1946), Alpert (1950), and Wexler (1951), and the finer structure has lately been described by Knigge (1954a, b). Quite recently Holmes (1955) published a detailed study concerning the histological variation in the adrenal cortex of this animal, with particular reference to the $\mathbf{X}$ zone. There is, however, no information on the histogenesis of this organ. It is the purpose of the present study to supplement the scanty knowledge regarding this by following the postnatal development of the adrenal cortex of the hamster. The voluminous literature on the morphology of the adrenal gland was recently surveyed by Bachmann (1954). I shall, therefore, only refer to recent selected works which concern with the problems under consideration here. 


\section{Material and Methods}

One hundred and thirty golden hamsters of both sexes were employed in this study, at ages ranging from immediately after birth to 300 days. The fixatives were Bouin's, Ciaccio's fluids and Zenkerformol. Fixation in Ciaccio's fluid was usually followed by post-chromation in 3\% potassium bichromate for four to seven days. The materials fixed in Zenker-formol were subsequently placed in equal parts of $5 \%$ potassium bichromate and $2 \%$ chrome alum for two days at $37^{\circ} \mathrm{C}$ in the manner described by Kiyono. Paraffin embedding was used, and sections were cut serially. at $5 \mu$. Most of the sections fixed in Bouin's fluid were stained with Mayer's hematoxylin and eosin, and some by the periodic acid-Schiff (PAS) method. In addition, Heidenhain's azan stain and Gomori's silver method were employed. The meterials fixed in Zenker-formol or Ciaccio's fluid were generally stained with Heidenhain's iron hematoxylin. For some sections prepared after Ciaccio's fixation alcoholic Sudan black B was used in staining.

\section{Observations}

\section{A) Postnatal histogenesis}

At birth and 1-day-old: The adrenal gland is generally enclosed in a cellular capsule consisting of four to five layers of young connective tissue cells with round or rod-shaped nuclei. The adrenal is roughly divided into peripheral cortical and central medullary tissues, although in the centre of the gland the cortical cells in cords or groups are intermingled with the medullary tissue. The cortex is thin and has two vaguely defined zones; an outer and an inner. In the outer zone immediately beneath the capsule, the cells are smaller and packed more closely together into irregular masses or cords parallel to the surface of the gland. Their nuclei are spherical or oval with a loose chromatin network containing fine chromatin particles or nucleoli. The cytoplasm stains lightly with the usual stain. These cells contain numerous granular and thin rod-like mitochondria uniformly distributed throughout the cytoplasm (fig. 7). The inner zone has irregularly arranged cells which are larger and more eosinophilic than the cells of the outer zone. The nuclei are round or oval and are larger than those of the outer zone. They are poor in chromatin and usually contain relatively prominent nucleoli or chromatin particles. 
The cytoplasm is laden with mitochondria which are mostly rod-shaped or filamentous and partly granular in shape (fig. 8). In the inner zone are occasionally seen far larger cells with a larger nucleus which is generally elliptical and sometimes wrinkled. In sections stained with iron hematoxylin its cytoplasm is found to have coarse granules or droplet-like structures. A small ganglion is often seen close to the adrenal, and younger ganglion cells are rarely found within the capsule of the gland.

2- and 3-day-old: The cortico-medullary boundary is interdigitated. The cortical cells are scattered, singly or in small groups, among the medullary cells, but their number is considerably reduced.

4- and 5-day-old: The capsule consists of an interlacing layer of fibroblasts and loose fibrils. The capsule is considerably thick in some places, particularly at the hilar region where a large vein from the medulla leaves or nerve bundles enter. Small groups of cortical cells are occasionally present in such places. The fibroblasts of the capsule are more or less distinctly marked off from the adjoining cortical cells. Some degree of differentiation is apparent in the outer zone of the cortex. The cells of the outermost portion of the zone are somewhat increased in the size of both nucleus and cytoplasm, while those of the inner portion remain about the same size as before (fig. 1). However, such differentiation is not apparent equally around the entire periphery of the cortex, and the outer zone remains unchanged in many places. A few larger cells in the inner zone have a homogeneously eosinophilic shrunken cytoplasm, undergoing degenerative process.

6- to 8.day-old: The capsule varies regionally to some extent in thickness and structure. On the surface parallel to the long axis of the elliptical adrenal gland, it is denser and thinner, and its cells are more elongated with spindle-shaped, long elliptical or rod-shaped nuclei. At the corner of the surface or the hilum, however, the capsule is relatively thick and loosely fibrillar, consisting of irregularly arranged fibroblasts with elliptical or round nuclei. The cortex is more distinctly distinguished from the medulla, because the cells of the inner zone become more eosinophilic while the medullary cells have a basophilic cytoplasm. In the inner zone the cells with larger nuclei, though individually variable in occurrence, become generally reduced in number.

9. and 10-day-old: The thicker part of the capsule is divided into an outer fibrous layer and an inner cellular. The inner layer 
just outside the cortex is composed of irregularly packed fibroblasts with scanty light cytoplasm and nuclei varying in shape from ovoid to long elliptical. The capsule occasionally contains cortical cells in small groups or singly. When stained with iron hematoxylin after fixation in Zenker-formol, the capsule becomes brownish blue, and its elements can be readily distinguished from the cortical elements which stain deeply blue. The outer zone of the cortex exhibits a considerable degree of differentiation, consisting mainly of cells, arranged in rounded masses or loops, with a relatively abundant finely granular, light cytoplasm and relatively large nuclei. Immediately internal to such outer zone there is a very thin transitional layer, which, consisting of closely packed cells with scanty cytoplasm and small, round or oval, darker nuclei, is transitional in appearance toward both the outer zone and the underlying inner zone. Delicate mitochondria which are usually granular are evenly distributed throughout the cytoplasm of the cells of both the outer and transitional zones. The cells of the inner zone become increased in the cytoplasmic staining with eosin. Their mitochondria are larger than those of the cells of the outer zone. They appear as granules and thin rods, and the granular forms are more increased in number than in the previous stage. In the inner portion of the inner zone, occasional cells possess coarse granules or droplet-like structures.

12- and 13-day-old: The argyrophile fibres enclose the cell masses in the outer zone. Such fibres divide the inner zone into irregularly arranged cell compartments. The fine connective tissue fibrcs which stain positively after application of PAS reagent exhibit similar features as the argyrophile fibres. With the PAS technique the finely granular cytoplasm of the cells of the outer zone gives a faint reaction. In the cells of the outer zone, vacuoles of extremely small size are often seen among the delicate granular mitochondria in the cyto. plasm (fig. 9). In the outer portion of the inner zone, cells with numerous granular mitochondria of uniform size predominate in number, while those of the inner portion contain rod-shaped mitochondria besides the granular forms. The cells with coarse granules are diminished in number. The larger cells with large nuclei are also rarely present.

15-day-old: At this age the outer zone acquires the definite structure which characterizes the zona glomerulosa (fig. 2). The cells of this zone are commonly arranged in small masses, loops or short strings, separately by delicate connective tissue fibres. They have 
finely granular light cytoplasm which does not show any distinct cell boundary. Their nuclei are large, elliptical with small eosinophilic nucleoli, and chromatin particles are dispersed on a fine linin net. The transitional zone which is continuous in appearance with both the glomerulosa and fasciculata is found in some places. The cells of the inner zone are polyhedral in shape, and each contains a larger round nucleus imbedded in an abundant, eosinophilic, granular cytoplasm. Both large cells with large nuclei and cells containing coarse granules are reduced in number, and are of rare occurrence. Among the medullary zells the cortical cells are present only in small numbers.

18- and 20-day-old: The inner zone begins to be arranged in a roughly fasciculate manner. The fascicular arrangement, however, is not so apparent in sections stained with hematoxylin and eosin, because it is not so regular and distinct as seen in some other species. When the connective tissue stain is employed, the cells are found arranged in more or less fascicular cords with delicate strands of connective tissue. Between the medullary tissue the interlocking cortical cells, singly or in small groups, are reduced in number, and their nuclei often appear shrunken with a wrinkled nuclear membrane.

25-day-old: The capsule is fibrous and dense except in the hilumlike portion. The inner zone begins to show a differentiation into two zones, an outer region and an inner, although this division is not always distinct in each case. The outer region shows gradual conversion into the typical adult fasciculata and the inner, into the reticularis. In males the outer region exhibits a more or less fascicular arrangement, and its cells are large, polyhedral, considerably eosinophilic and contain a round nucleus with one to three prominent nucleoli. The cells of the inner region are disposed more irregularly and have more eosinophilic cytoplasm and somewhat smaller, more deeply staining nuclei than those of the outer region. In females the outer region of the inner zone is similar in appearance as in males. The innermost several layers adjacent to the cortico-medullary boundary are composed of small cells with very closely packed nuclei. Delicate connective tissue fibres enclose individual cells or small cell masses.

30-day-old: At this age the three cortical zones are first distinguishable. The outer region of the former inner zone, zona fasciculata, occupies more than one half the width of the cortex. The fasciculata cells contain numerous granular mitochondria of relatively large size. In addition, somewhat larger spherical bodies which are stained like the mitochondria are often intermingled among the mitochondria (fig. 
10). A transition can be found from the granular mitochondria to these spherical bodies. The mitochondria and spheres are distributed throughout the cytoplasm except for a clear paranuclear area. The innermost zone, zona reticularis, varies in structure in both sexes (figs. $3,4)$. In the male adrenal the reticularis cells have an abundant eosinophilic cytoplasm which is more or less coarsely granular. Their nuclei are somewhat variable in shape; many of them are spherical, and some, irregular with shrunken nuclear membrane. The spherical nuclei are similar to those of the fasciculata cells, but their nucleoli are indistinct. The shrunken nuclei of varying shape tend to be darker without a distinct chromatin network. The reticularis contains some degenerative cells, the nuclei of which occur as darkly staining debris imbedded in a rounded, intensely and homogeneously eosinophilic cell body or as those with coarse clumps of chromatin adherent to the nuclear membrane. The reticularis of the female cortex is a thin layer composed of closely packed cells, which are almost similar in nuclear morphology to those of the fasciculata, although they are smaller than the latter. A few cells of this zone show cytoplasmic vacuolation. Some cells are found undergoing degenerative changes, too.

35- and 40-day-old: In some places the zona glomerulosa is continuous with the zona fasciculata without any transitional layer. The .cells of both the glomerulosa and the transitional layer contain granular mitochondria which are more delicate and less numerous than those of the fasciculata cells. The glomerulosa cells often possess -minute vacuoles among the mitochondria. The mitochondria of the cells of the outer fasciculata are the same, in feature, as those described for the former stages. In the cells of the inner fasciculata, short rod-shaped mitochondria predominate in number. The reticularis occupies nearly one-fourth of the total cortical width in males, and one-eighth in females (figs. 5,6). The cells of the reticularis of the male are generally polyhedral and somewhat angular in shape. They contain considerably large spherical bodies of varying size in addition to relatively small numbers of rod-shaped or filamentous mitochondria (fig. 11). These bodies sometimes fill the cell body, and some of them appear as droplet-like structures with somewhat lightly staining content. With Sudan black B after fixation in Ciaccio's fluid and postchromation in $3 \%$ potassium bichromate, they stain blue black. Occasional cells show varying degrees of shrinkage and nuclear degenerative changes. The raticularis cells of the female hamster contain 
mitochondria and spheres such as seen in the fasciculata cells, although the spheres are somewhat unequal in size. The large spherical bodies stained with Sudan black B such as seen in males are not observed here. Some of the reticularis cells have a vacuolated cytoplasm. The degenerating and dead cells are seen more frequently than in males.

45- and 50-day-old: The glomerulosa cells are usually grouped in clusters, short cords and loops. The clusters and cords are enclosed by delicate connective tissue fibres, being relatively distinctly demarcated from the fasciculata. When the glomerulosa cells are arranged in loops at the ends of the radial cords, they are often associated with the fasciculata through a thin transitional layer intervening between the glomerulosa and the fasciculata. In the fasciculata, delicate connective tissue fibres, while sending very fine fibres crosswise, run inwards along the irregularly radial cell columns. In females the fasciculata contains vacuolated cells in very small numbers. In the male the reticularis cells are generally polygonal in shape except in the portion just adjacent to the fasciculata, where they appear somewhat compressed, with more or less elongated nuclei, in the radial direction of the cortex. The nuclei of the reticularis cells generally show indistinct chromatin network and less strained nuclear membrane and are darker than those of the fasciculata cells. In the female many of the small reticularis cells possess a foamy cytoplasm. In some cases, fat cell-like elements with high degree of cytoplasmic vacuolation lie in considerable numbers along the cortico-medullary boundary. Degenerative cells are of constant occurrence in both sexes and are found more frequently in females than in males. The stromal fibrous tissue of the reticularis is denser in both sexes than in the former stage. In neither of the two sexes, however, there is a particular boundary layer of connective tissue between the cortex and medulla.

55- and 60-day-old: In females the collagenous fibres of the reticularis become denser and more abundant than before. A relatively thicker fibrous layer appears at the cortico-medullary boundary. The blood vessels in the reticularis have a considerably wide lumen.

65- and 70-day-old: In males the innermost portion of the fasciculata contains a few cells with large vacuoles. These vacuoles are often in the process of coalescence, forming a single vacuole of extremely large size. In the male reticularis the fibrous connective tissue is considerably increased in amount. The reticularis cells which contain small spherical bodies or coarse granules stained with Sudan black B after Ciaccio's fixation tend to be somewhat condensed in 
cytoplasm. Therefore, their nuclei appear more or less packed when compared with those of the fasciculata cells. In females a few of the fasciculata cells are degenerative in appearance with a foamy cytoplasm, although they do not occur in all cases. The reticularis cells in females are diminished in number in some places, where the fibrous stroma with the blood vessels appears spongy. Some of the reticularis cells are vacuolated with fine vacuoles. In some few cases the reticularis is composed almost of such cells.

75- to 90-day-old: In males the fasciculata contains degenerative elements, which appear as very large vacuoles or coarsely vacuolated cells, mostly in the innermost portion of the zone. In the reticularis, degenerating cells of different stages or eosinophilic debris are of common occurrence. The fibrous stroma is considerably increased in amount, and it contains small numbers of cells with yellowish brown pigment granules of varying size, which stain darkly red with PAS technique. These pigment cells are variable in number in different cases and are rare in some few cases. In females a few degenerative elements as seen in the former stages are scattered in the fasciculata. They are not observed in some cases. In females no pigment cells occur in the stroma of the reticularis except in a case of 80 days.

100-to 110-day-old: At the hilum-like place where a large blood vessel leaves through the capsule, the capsule is relatively thickened, consisting of fibroblasts with round or oval nuclei. A few small groups of the glomerulosa cells and a rare ganglion cell are observed here in some cases. Although the fibroblasts may be similar in appearance to the glomerulosa cells in hematoxylin-eosin sections, a transition from the former to the latter can hardly be found. This finding is ascertained particularly under a high power examination in sections with mitochondrial stains. The reticularis of the female hamster tends to show a reduction in number of the parenchymal cells, and its stromal tissue including the blood vessels with wide lumen becomes increased in amount. Thus this zone appears somewhat spongy in some parts. In other parts the reticularis has already disappeared, and the fasciculata extends as far as the cortico-medullary boundary. Pigment cells, though relatively in small numbers, occur in the stroma of the reticularis in some females as in males.

120-day-old: In males the reticularis cells contain PAS-positive, dust-like granules, which are however invisible in hematoxylin-eosin sections. In females a layer of connective tissue with blood vessels intervenes occasionally between the fasciculata and the reticularis. 
Many of the reticularis cells have foamy cytoplasm and shrunken nuclei. Small cells containing yellow-brown pigment are distributed in the stroma of the reticularis.

140-and 150-day-old: In females the reticularis becomes more diminished in thickness. Fat cell-like elements in degeneration occur rarely in the fasciculata and sometimes in the reticularis.

160. to 180-day-old: In males the cytoplasm of many reticularis cells becomes more or less condensed and frequently contains fine PAS-positive granules. Their nuclei are generally shrunken. Thus some parts of the reticularis, owing to a decrease in amount, appear spongy with the remaining blood vessels and stroma. Pigment cells are frequently seen in the interstitial tissue, and their pigment granules of varying size are positively stained with the PAS technique. In females the innermost portion of the cortex varies in appearance in different places. In some places the reticularis, though thin, exists, and in others the fasciculata extends as far as the cortico-medullary boundary, and further in others a spongy tissue with scattered vacuolated cells or cell debris is found instead of the reticularis. The reticularis cells of the female adrenal contain fine granules staining darkly red with the PAS technique as those of the male adrenal.

200- to 300-day-old: In both sexes yellowish brown pigment granules are frequently encountered in the reticularis cells. Further, certain of the fasciculata cells contain the pigment granules in small amounts, too. In females 'a thicker layer of connective tissue exists between the cortex and the medulla than in males.

\section{B) Postnatal growth and mitotic activity}

The width of the adrenal cortex and the ratio of the component zones at varying ages are shown in table 1 . Measurements were made approximately at the middle of the gland on the flat sides. The width of the cortex shows gradual increase in both sexes up to about 20 days of age, but thereafter the male cortex appears to exceed the female one in width. The cortex attains its adult width at about 65 to 70 days in both sexes. In young animals under about 20 to 25 days of age the cortex is divided into outer and inner zones. From the 30th days on, the adult three zones can be distinguished. The reticularis varies definitely in both sexes not only in structure but also in width. 
Table 1. Width of the cortex and ratio of width of each zone at varying ages.

\begin{tabular}{|c|c|c|c|c|c|c|c|c|c|}
\hline $\begin{array}{c}\text { Age } \\
\text { (days) }\end{array}$ & Sex & $\begin{array}{c}\text { No. of } \\
\text { animals }\end{array}$ & $\begin{array}{c}\text { Width } \\
(\mu)\end{array}$ & Ratio & $\begin{array}{l}\text { Age } \\
\text { (days) }\end{array}$ & Sex & $\begin{array}{l}\text { No. of } \\
\text { animals }\end{array}$ & $\begin{array}{c}\text { Width } \\
(\mu)\end{array}$ & Ratio \\
\hline 0 & $\mathrm{~m}$ & 2 & 86 & $1: 1.5$ & 55 & $\mathrm{~m}$ & 2 & 546 & $1: 13.4: 6.4$ \\
\hline 0 & $\mathbf{f}$ & 1 & 80 & $1: 1.3$ & 55 & $f$ & 2 & 445 & 1:13.2:2. 3 \\
\hline 1 & $\mathrm{~m}$ & 2 & 83 & $1: 2$ & 60 & $\mathrm{~m}$ & 1 & 530 & $1: 13.4: 6$ \\
\hline 2 & $m$ & 2 & 77 & $\mathrm{I}: 1.9$ & 60 & $f$ & 2 & 397 & $1: 11.2: 2.2$ \\
\hline 2 & $\mathbf{f}$ & 1 & 84 & $1: 1.5$ & 65 & $\mathbf{m}$ & 1 & 624 & $1: 16.7: 5.7$ \\
\hline 3 & $\mathrm{~m}$ & 1 & 95 & $1: 1.8$ & 65 & f & 2 & 442 & $1: 13.1: 2.4$ \\
\hline 3 & f & 1 & 81 & $1: 1.8$ & 70 & $\mathbf{m}$ & 2 & 572 & $1: 14.2: 6.6$ \\
\hline 4 & $\mathrm{~m}$ & 2 & 89 & $1: 1.3$ & 70 & $\mathbf{f}$ & 3 & 407 & 1:12.2:2.5 \\
\hline 4 & $\mathbf{f}$ & 2 & 92 & $1: 1.6$ & 75 & $\mathrm{~m}$ & 1 & 639 & $1: 16: 7$ \\
\hline 5 & $\mathrm{~m}$ & 2 & 83 & $1: 1.7$ & 75 & $\mathbf{f}$ & 2 & 397 & $1: 13.5: 0.9$ \\
\hline 5 & f & 2 & 88 & $1: 1.2$ & 80 & $\mathrm{~m}$ & 2 & 553 & $1: 14.5: 5.6$ \\
\hline 6 & $\mathbf{f}$ & 1 & 97 & $1: 1.2$ & 80 & $\mathbf{f}$ & 2 & 406 & $1: 13.2: 1.5$ \\
\hline 7 & $\mathbf{f}$ & 1 & 116 & $1: 1.6$ & 85 & $\mathrm{~m}$ & 1 & 585 & $1: 15.5: 6$ \\
\hline 8 & $\mathrm{~m}$ & 2 & 140 & $1: 1.8$ & 85 & $\mathbf{f}$ & 1 & 455 & $1: 14.5: 2$ \\
\hline 8 & $\mathbf{f}$ & 1 & 101 & $1: 1.9$ & 90 & $\mathrm{~m}$ & 1 & 611 & 1:16.3: 6 \\
\hline 10 & $\mathrm{~m}$ & 2 & 122 & $1: 1.8$ & 90 & $\mathbf{f}$ & 2 & 478 & $1: 15.7: 1.5$ \\
\hline 10 & $\mathbf{f}$ & 2 & 118 & $1: 1.9$ & $9 \overline{5}$ & $\mathrm{~m}$ & 1 & 598 & $1: 15.3: 6.6$ \\
\hline 13 & $\mathrm{~m}$ & 2 & 125 & $1: 2.3$ & 95 & $f$ & 2 & 436 & $1: 14: 1.8$ \\
\hline 13 & $\mathbf{f}$ & 1 & 83 & $1: 1.8$ & 100 & $\mathrm{~m}$ & 4 & 579 & $1: 15: 5.9$ \\
\hline 15 & $\mathrm{~m}$ & 2 & 163 & $1: 4$ & 100 & f & 2 & 458 & $1: 14.1: 2.2$ \\
\hline 15 & $\mathbf{f}$ & 2 & 166 & $1: 4.3$ & 105 & f & 1 & 509 & $1: 17.1: 1.5$ \\
\hline 18 & $\mathrm{~m}$ & 1 & 224 & $1: 6.3$ & 110 & f & 1 & 484 & $1: 16: 1.6$ \\
\hline 18 & $f$ & 1 & 219 & $1: 7.6$ & 120 & $\mathrm{~m}$ & 2 & 605 & $1: 16: 6.2$ \\
\hline 20 & $\mathrm{~m}$ & 1 & 247 & $1: 10.4$ & 120 & $f$ & 2 & 482 & $1: 15.4: 2.1$ \\
\hline 20 & $f$ & 2 & 229 & $1: 6.5$ & 140 & $\mathrm{~m}$ & 2 & 585 & $1: 15: 4.7$ \\
\hline 25 & $\mathrm{~m}$ & 4 & 327 & $1: 10.4$ & 140 & $f$ & 1 & 473 & $1: 14.8: 1.4$ \\
\hline 25 & $f$ & 2 & 229 & $1: 7.8$ & 150 & $\mathrm{~m}$ & 1 & 462 & $1: 12.5: 4.3$ \\
\hline 30 & $\mathrm{~m}$ & 3 & 367 & $1: 7.6: 5.1$ & 160 & $\mathrm{~m}$ & 2 & 504 & $1: 12.6: 4.4$ \\
\hline 30 & $f$ & 2 & 266 & $1: 6.8: 2.4$ & 160 & f & 3 & 336 & $1: 12.2: 0.9$ \\
\hline 35 & $\mathrm{~m}$ & 2 & 380 & $1: 8: 4.5$ & 170 & f & 1 & 442 & $1: 15: 1$ \\
\hline 35 & $\mathbf{f}$ & 2 & 299 & $1: 8.8: 1.2$ & 180 & $\mathrm{~m}$ & 1 & 507 & $1: 14: 4.5$ \\
\hline 40 & $\mathrm{~m}$ & 1 & 398 & $1: 10: 4.5$ & 180 & $\mathbf{f}$ & 1 & 423 & $1: 14: 1.2$ \\
\hline 40 & $\mathbf{f}$ & 1 & 346 & $1: 10.8: 1.5$ & 200 & $\mathrm{~m}$ & 1 & 462 & 1:8.3:3.1 \\
\hline 45 & $\mathrm{~m}$ & 2 & 471 & $1: 11.3: 4.5$ & 200 & $\mathbf{f}$ & 1 & 423 & $1: 14: 1.2$ \\
\hline 45 & $\mathbf{f}$ & 2 & 320 & $1: 11.2: 1.5$ & 240 & $\mathbf{m}$ & 1 & 524 & $1: 15.1: 4$ \\
\hline 50 & $\mathrm{~m}$ & 2 & 483 & $1: 11.5: 5.9$ & 250 & $\mathrm{~m}$ & 1 & 611 & $1: 16.7: 5.7$ \\
\hline 50 & $\mathrm{f}$ & 2 & 382 & $1: 11.6: 1.9$ & 300 & $\mathrm{~m}$ & 1 & 546 & $1: 16.2: 3.7$ \\
\hline
\end{tabular}

The frequency of mitosis in the cortical cells at varying ages is presented in table 2. Mitoses were counted in ten sections nearly through the centre of the gland, and the average number per section is shown for the individual zones. No mitotic figures were seen in the reticularis. 
Table 2. Number of mitoses of adrenal cortical cells at varying ages.

Average no. of mitoses per section

Age Sex $\begin{gathered}\text { No. of } \\ \text { animals }\end{gathered}$ (glom.) $\begin{gathered}\text { Outer zone Inner zone } \\ \text { (fasc.) }\end{gathered}$

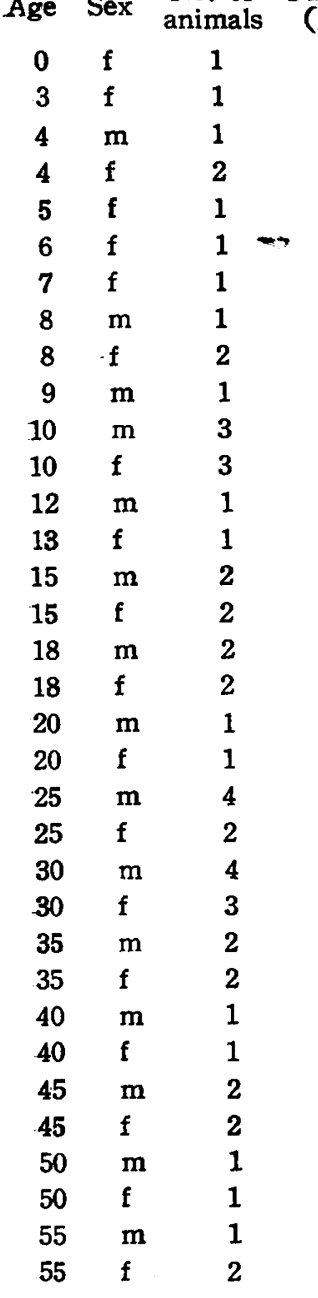

$2.8 \quad 2$.

3.0

2.5

3.0

0.9

4.3

2.1

3.9

2.2

1.1

1.5

1.7

2.4

1.2

1.2

1.5

1.5

1.5

1.3

1.1

1.3

1.3

0.8

0.8

0.7

0.7

1.1

0.7

0.4

0.8

0.8

0.3

0.4

0.4
2.6

2.1

2.3

2.3

0.4

3.9

2.4

4.3

2. 6

2.4

1.9

3.0

5.2

2.7

3.1

4.8

2.8

1.5

2.8

1.9

1.5

4.4

2.4

2.5

2. 3

3. 6

3.7

3.5

2.4

1.2

3.7

2.2

0.3

0.6

Average no. of mitoses per section Age Sex $\begin{gathered}\text { No. of Outer zone Inner zone } \\ \text { animals (glom.) }\end{gathered}$ $60 \mathrm{~m} \quad 1$ 0.9

3.0 60 65

f 2

1.0

1.1 65 70 70 $75 \quad \mathrm{~m}$ m 1

0.8

0.9 f 2

0.8

1.8

m 2

0.2

0.9

$0.4 \quad 1.3$

$0.4 \quad 0.8$

$\begin{array}{lll}75 & f & 1\end{array}$

0

0.2

$80 \quad \mathrm{~m} \quad 2$

0.1

0.3

80 f 3

0.1

0.3

$85 \mathrm{~m} \quad 1$

0

0.2

$85 \mathrm{f} \quad 1$

0.2

1.1

$90 \mathrm{~m} \quad 1$

0.1

0.1

$90 \mathrm{f}$

0.3

0.4

$95 \mathrm{~m} \quad 1$

0.1

1.2

0.2

0.7

$100 \mathrm{~m} \quad 2$

0.6

0.3

$100 \mathrm{f} \quad 1$

0.4

0

105 f 1

1.0

0.7

$110 \mathrm{~m} \quad 1$

0.5

0.1

0.5

0.2 ;

120

0.4

0.3

0.3

0

140

0.1

0.1

150

160

0.3

0

0.2

0.1

160

170

0

0

180

180

0.2

0.3

0.1

0.1

0.1

0

200

200

250

0

0

0

0

\section{Discussion}

\section{A) Zoning}

Histologically it has been customary to divide the adrenal cortex of mammals into three zones; the zona glomerulosa, fasciculata and reticularis. This classical zoning has doubtless continued to be popular and practical in normal and pathological histology, although certain different classifications were proposed for some species. In the newly- 
published 'Handbuch der mikroskopischen Anatomie' edited by Möllendorff and Bargmann, Bachmann (1954), presenting a detailed criticism on the zoning of the adrenal cortex of mammalia, stated that until a better zoning is established, the classical terminology should be retained, if the pattern of the distribution of lipoid is added, in describing the adrenal cortex of mammalian species. In practice, since the degree of cytoplasmic vacuolation, like the morphological appearance, is different in different zones, lipoid studies are suggestive of a zoning in the cortex. Particularly the zona fasciculata of most mammals is composed of cells characterized by numerous cytoplasmic lipoid vacuoles and contrasted by its high lipoid content with the outer and inner zones. On the other hand, however, the hamster's cortex including the fasciculata contains little lipoid and presents a very peculiar appearance. Nevertheless, owing to differences in morphology of the cells, three zones can be made out. For the sake of accuracy and convenience, it would be better to refer to these zones under the name in common usage as also employed by investigators working on this animal, such as Alpert (1950), Wexler (1951), and Knigge (1954a, b).

\section{B) Zona glomerulosa}

In connection with the dynamic structure of the adrenal cortex, there is no unanimity of opinion regarding the morphological significance of the zona glomerulosa. Perhaps the view formerly commonly accepted is that this zone provides for the growth of the cortex and for the replenishment of the inner cortical region, or that this zone is composed of relatively immature cortical cells which gradually mature. move inwards and become transformed into the fasciculata cells and later into the reticularis cells (Gottschau's hypothesis, cell migration theory). In recent years, however, the glomerulosa, like the fasciculata, has been regarded as a well-differentiated region with secretory activity. Some American workers (Deane and Greep, 1946; Deane, Shaw and Greep, 1948; Greep and Deane, 1949; and others) postulated that the zona glomerulosa may be concerned with the regulation of salt metabolism agaist the inner zones which probably regulates carbohydrate and protein metabolism, and therefore that the glomerulosa is an autonomous region independent morphologically and functionally from the remainder of the cortex (zonal or dualistic theory). Recently Ando (1953) suggested that although the cortical cells gradually migrate from without inwards, all the zones including the zona glomerulosa have their respective secretory functions. Subsequently Yoshimura (1954) held the dualistic theory from a morphological point of view. 
On the other hand, however, this investigator, proposing that the glomerulosa secretes the same hormones as the fasciculata does, was inclined to the unitalistic concept from a functional point of view. Furthermore, Dallwig (1954) also, in studying some histological changes of the cortex after thirst in the rat, suggested the relative independence of the glomerulosa. In any case, according to the second theory, there is agreement that the glomerulosa may be regarded as an actively secreting zone. The other modern view concerned with the subject under consideration is the one advocated by Tonutti (1941, 1942a, b). This author, in studying the dynamic structure of the cortex under various experimental conditions, came to the conclusion that the glomerulosa becomes transformed into the fasciculata under circumstances which produce a need for increased amounts of cortical hormones (progressive transformation), and that when the cortical activity becomes less necessary, the glomerulosa becomes more apparent (regressive transformation). Thus he named the glomerulosa including the capsule 'äusseres Transformationsfeld', which he regarded as representing a reserved zone for the fasciculata. This transformation theory of Tonutti is supported by some German schools (Bachmann, 1953, 1954). In a previous paper I observed, in the guinea pig, that the glomerulosa cells show various characteristic features of highly differentiated cells, and came to the conclusion that at least in normal guinea pigs this zone may well be regarded as responsible for individual function (Ito, 1952). In the hamster Knigge (1954b) noted that after acute starvation the constituent cells of the zona glomerulosa exhibit various changes which are considered to reflect their increased activity. According to my present observations, on the first day of life the cortex of the hamster shows a differentiation into two zones; an outer zone composed of relatively small cells and a deeply-lying inner zone consisting of larger cells. As development proceeds, the smaller cells of the outer zone become gradually enlarged to differentiate into the glomerulosa cells (figs. 1,2). Mitochondria in the less differentitated cells are granules and rods in shape (fig. 7). As the cells become differentiated, the rod-shaped mitochondria become reduced in number. Thus the definite glomerulosa cells contain only granular mitochondria as Knigge (1954b) reported. Furthermore, in the fully developed cells, fine vacuoles often occur among the mitochondria (fig. 9). Such vocuoles are found only in this zone, but not in the other zones. Knigge (1954b) also described that the glomerulosa cells are unique in that they contain the osmiophilic lipid droplets which appear as de- 
lineated vacuoles after fixation in Regaud's fluid. At about 15 days of age the detailed structure of the zona glomerulosa attains practically the definite condition, and then few changes are noticeable. From the above it may be said that the glomerulosa cells are characteristically well-differentiated. At least in normal hamsters it seems reasonable to ascribe some secretory activity to this zone. However, if the animal is laid under a pathological state which may require higher activity of the adrenal cortex, there might be the possibility that the glomerulosa, leaving its proper activity aside, may take over the function of the fasciculata, as Tonutti claimed. Further studies are necessary before it can be answered whether or not the glomerulosa may transform itself into the fasciculata under particular circumstances.

As is well known, the transitional zone is very characteristic in the rat, also called a sudanophobe zone. Accordingly, this zone has been investigated in detail mainly in this animal, and recent investigators have inclined to the view that this zone serves as a reserved region for the zona fasciculata (Yoshimura, 1954; Mori and Ando, 1955). Aside from the species which are not concerned in this paper, a brief reference will be given from the standpoint of the present study in the hamster. Recently Cater and Lever (1954) made extensive studies on the transitional zone (zona intermedia) in many species and stated that a well-defined zona intermedia is apparently associated with a zona glomerulosa of regular form (column or rosette), whereas it is ill-defined in adrenals where the zona glomerulosa is a diffuse cell collection. In the hamster Knigge (1954a) mentioned that the presence of transitional cells is more apparent in areas where the constituent cells of the zona glomerulosa and zona fasciculata are joined in a continuous column. I also observed that there is occasionally a thin layer in which the cells appear rather compressed with aggregated nuclei and scanty cytoplasm, and that this transitional zone is relatively well-defined in areas where the glomerulosa is arranged in loops with arched ends as pointed by Cater and Lever (1954). This zone remains less differentiated in appearance and seems to undergo a compression from outside and inside through the growth of the glomerulosa and fasciculata. Thus the transitional zone, if present, shows an appearance like the zone of compression described by Mitchell (1947) in the rat.

\section{C) Zona fasciculata}

The zona fasciculata of the hamster's cortex presents extremely peculiar cellular pictures unlike that in other common species. In 
most animals the fasciculata is formed of characteristic cells which have numerous lipoid droplets in the cytoplasm. In usual histological sections the lipoid is dissolved out, and the cells appear characteristically vacuolated, hence also called spongiocytes. Owing to the abundance of these characteristic inclusions of the fasciculata cell, the cortex is a lipoid-rich organ. On the contrary, the cortex of the hamster is peculiar in that the fasciculata contains little sudanophil lipoid (Peczenik, 1944 ; Koneff, Simpson and Evans, 1946; Alpert, 1950; and others). Thus the cortex is characterized by the lack of lipoid droplets and is called 'lipoid-poor' type in contrast to the 'lipoid-rich' type of other species (Alpert, 1950). Concerning the cytology of the fasciculata cells in the hamster, Knigge $(1954 a, b)$ gave a detailed description. In the present study some considerations will be given below mainly from the histogenetic standpoint. The establishment of the cell arrangement and cell differentiation can serve as the criteria of histological completion of the fasciculata. During the early stages of development the less differentiated cells of the inner zone which is topographically similar to the fasciculata are irregularly arranged in groups separated by delicate argyrophile fibres. After 18 to 20 days of age they become characteristically arranged in radial cords with strands of connective tissue and blood vessels running from without inwards. The connective tissue fibres are relatively delicate, and the fascicular arrangement of this zone is not so definite as in other animals. Therefore, the arrangement characteristic of this zone is sometimes demonstrated not clearly in hematoxylin-eosin preparations. On the other hand, the cells gradually acquire more eosinophilic granular cytoplasm, and their cytological differentiation progresses. In hamsters under 10 days old, mitochondria of the less differentiated cells are mostly filamentous, rod-shaped, and partly granular in shape (fig. 8). Then the granular mitochondria become gradually increased in number until at 20 days the cells of the outer portion of the inner zone are filled with somewhat enlarged granular mitochondria. After 25 to 30 days of age the cells of the outer fasciculata contain mediumsized spherical bodies or droplet-like structures in addition to the granular mitochondria (fig. 10). In the inner portion of the fasciculata, mitochondria generally remain rod-shaped. Thus the fasciculata attains essentially adult characteristics in details of cell structure at the age of 25 to 30 days. The small spherical bodies distributed among the mitochondria were referred to as liposomes by Knigge (1954a, b). According to him, the liposomes exhibit an intense affinity for iron 
T. ItG

hematoxylin like the mitochondria and are differentiated from mitochondria only' on the basis of their greater size. As suggested by this investigator, these spherical bodies appear to be transformed from the granular mitochondria, because transitions can be found from the latter. They begin to appear simultaneously with the differentiation of the fasciculata and represent the distinctive features of the cells. From these considerations it seems reasonable to regard these cytoplasmic structures as functionally essential to the activity of the fasciculata cells.

In the fasciculata cells of the hamster a clear juxta-nuclear area, which was believed to be the negative image of Golgi-apparatus (Knigge, 1954a, b), is sometimes found. According to the present observations, such areas are occasionally weekly stained with the PAS technique. Frazão (1952) observed, in a human embryo of 4 months, that some cortical cells of the adrenal show a PAS-positive Golgi-zone. The same seems to be true of some fasciculata cells in the hamster.

References to the presence of degenerative cells in the zona fasciculata under normal conditions have been few. Jayne (1953), in his paper which deals with the cytological changes in the adrenal gland of the rat with advancing age, notes that in all rats over 180 days old, degenerating cells were found throughout all zones of the cortex, and that in the fasciculata, pycnotic nuclei were more numerous in the cell columns situated directly internal to the degenerative area of the zona glomerulosa. In adult hamsters, cellular degeneration occurs in the fasciculata in both sexes, although its degree is relatively low. In males the degenerative cells appear often as cells with large vacuoles mostly in the innermost portion of the fasciculata from 65 to 75 days on. These vacuoles often coalesce into one or more larger spaces. In females, on the other hand, degenerating cells occur singly scattered throughout the fasciculata after the age of $\mathbf{4 5}$ days.

One of the age products in the cortical parenchymal cells is pigment. Jayne (1953) demonstrated, in 180- and 270-day-old rats, that yellow to brown pigment granules were present in scattered parenchymal cells of the inner half of the fasciculata. In hamsters older than 200 days the fasciculata cells often contain yellow to brown pigment in small amounts.

D) Zona reticularis

The present results indicate that the zona reticularis of the hamster's cortex begins to differentiate at 25 days of age and becomes apparent at 30 days. In the hamster Ortiz (1953) reported that at 30 
days of age ovulation is just beginning, and the testis which has recently descended to the scrotum is in a period of rapid growth. On the basis of these findings, this investigator considered this age as just prior to sexual maturity and a critical period in sexual development of this animal. It may be of some interest that the reticularis seems to become apparent at a period synchronous with the age considered as the onset of puberty. In the hamster the zona reticularis presents a structure of considerable complexity, because it varies in structure in both sexes. A sex difference in the structure of this zone was described by Knigge (1954a). According to him, the reticularis of the female consists of closely packed small cells with densely arranged nuclei, whereas that of the male is composed of larger cells with abundant cytoplasm and vesicular nuclei. More recently Holmes (1955), describing the histology of the adrenal cortex of the hamster with particular reference to the $\mathrm{X}$ zone, noted that the zona reticularis is absent in the mature male, while a narrow $\mathrm{X}$ zone is present in the mature unmated female. The present observations on the structure of the reticularis in the hamster largely confirm those of Knigge (1954a). In males the reticularis cells are almost as large as the fasciculata cells, but the cells of both zones are distinguished from each other on the basis of cytoplasmic and nuclear characteristics. The reticularis cells contain large spheroid bodies of varying sizes in addition to relatively small numbers of rod-shaped or filamentous mitochondria (fig. 11). These bodies are stained deeply with Sudan black $\mathrm{B}$ after Ciaccio's fixation. The nuclei with indistinct chromatin network appear somewhat atrophic as compared with those of the fasciculata cells. The nuclear membrane is less strained and sometimes wrinkled. In females, on the other hand, the reticularis is a thin layer composed of smaller closely disposed cells with densely packed nuclei (figs. 4, 6). Aside from cell size and consequently close aggregation of nuclei, these cells bear in cytological details some resemblance rather to the fasciculata cells. Holmes (1955) considered the reticularis of the cortex in mature males to be merely the inner region of the zona fasciculata, and that in mature females to be a narrow $\mathrm{X}$ zone. The present findings indicate, however, that the innermost region of the male cortex may well be regarded morphologically as a characteristic individual zone, namely, zona reticularis. Furthermore, although the innermost region of the female adrenal is characteristically different from the male reticularis, it would be convenient to call this region zona reticularis, too, in line with the usual zoning of mammalian 
adrenal cortex. Holmes (1955) regarded the reticularis of mature females as an $\mathrm{X}$ zone. At present, however, the evidence to identify the reticularis of mature female hamster with an $\mathrm{X}$ zone in the same sense as defined in the mouse is not yet sufficient. Therefore, I wish to call the inner region zona reticularis in both sexes. In the hamster the reticularis of the male is thicker than that of the female, and consequently the male cortex exceeds the female one in thickness (table 1). Peczenik (1944) reported, in this animal, that the male adrenal is heavier in weight than the female one. This result was subsequently confirmed by Koneff, Simpson and Evans (1946), Lavelle (1948), Keyes (1949), and Knigge (1954a). In the present study, although the weight of the adrenal was not measured, the impression was that the male adrenal is larger than the female one, because at the similar age the total number of serial sections of the adrenal was larger in males than in females. In the light of the data in table 1 , the sex difference in weight or volume of the adrenal gland seems to be attributable to the difference of the cortex or probably of the reticularis. The findings that the male reticularis shows a remarkable development and its cells contain characteristic inclusions may suggest that the reticularis is functionally the site of some activity, at least in males.

Degenerative process is of common occurrence in the zona reticularis of many species, although on this process is laid less stress at present than formerly (Bachmann, 1954). In the hamster, too, degenerating and dead cells of ten occur in the reticularis. Knigge (1954a) demonstrated that regressive changes are less frequently observed in male hamsters than in female. According to the present observations, it was also impressed that at and shortly after onset of puberty cell degeneration takes place somewhat frequently in females than in males. Later in adults degenerative and dead cells seem to be practically almost similar in occurrence in the two sexes. In certain animals, particularly guinea pigs, the reticularis was reported to contain dark cells which were regarded as representing cells in degenerative process (Ito, 1952). Recently Ehrenbrand (1954) suggested, in the guinea pig, that this type of cells represents a normal form of holocrine type. In the hamster the reticularis cells of the male have a considerably dark cytoplasm, and some of them are somewhat angular in shape, but any of them can hardly be distinguished in particular as dark cells. In females there are no cells similar to the dark variety of the reticularis cells. Furthermore, the degenerated cells of the reticularis of the $\mathrm{h}$ amster often appear as spherical, homogeneously eosinophilic masses. 
Such masses are disconnected from the neighbouring cells and present a colloid-like appearance. However, the further fate of these masses, for example, desquamation into the blood vessels, cannot be detected in the present study. Hence the possibility of the secretion of holocrine type as claimed by Ehrenbrand (1954) cannot be confirmed.

The pigment granules which are generally regarded as a normal product of old age have been found in the reticularis cells for many animals. Since the significance of the pigment of the cortical cells has been discussed at length (Rogoff, 1932; Bachmann, 1954), it need not be repeated here. The pigment will be but briefly stated in a generalized way. In male hamsters at 120 to 180 days of age and females at 160 to 180 days, fine PAS-positive granules, though invisible with hematoxylin and eosin, appear in the reticularis cells. The granules may be regarded as precursors of pigment granules, because they bear resemblance in appearance to pigment granules except in that they are not yet demonstrated in hematoxylin-eosin sections. Then, after 200 days, pigment appears as yellow to brown granulations in the reticularis cells. As already mentioned, the fasciculata cells occasionally contain pigment granules in ages over 200 days old. Although the nature and significance of the pigment cannot be determined, it can only be said that pigment is a normal inclusion of the reticularis in old hamsters of over a certain age.

\section{E) Capsule and Stroma}

The question of the capsule including the subcapsular region has received considerable interest in recent years, particularly in relation to the origin of the cortical cells, because the derivation of the adrenal cortical cells from the capsular or subcapsular tissue has been claimed by considerable numbers of investigators ( $Z$ wemer, Wotton and Norkus, 1938; Bachmann, 1939, and others). Recently Bachmann (1954) published an extensive review on this problem. In a previous study dealing with the guinea pig the transformation of capsular or subcapsular cells into glomerulosa cells could not be confirmed under normal conditions, although the subcapsular cells appeared less differentiated throughout postnatal life (Ito, 1952). In the present study careful consideration was given to this problem. In the hamster the capsule is loosely cellular in early stages of life and then becomes gradually denser with the increase of collagenous fibres until it obtains the almost definite structure at about 30 days of age. Even in adults, however, the capsular or subcapsular tissues occasionally remain sparsely fibrous in some few placss. As recognized by Knigge (1954a), 
the cells, fibroblasts, in such places are more or less similar in appearance to glomerulosa cells in sections after Bouin's and hematoxylin-eosin. This may be a reason why the source of the glomerulosa cells has been taken from the capsular or subcapsular cells. However, in preparations stained with iron hematoxylin after fixation in Zenkerformol followed by post-chromation, the difference between the fibroblasts in the capsular or subcapsular tissues and the glomerulosa cells appears more definite. Therefore, I am rather inclined to think that the transformation of fibroblasts into cortical cells does not occur in normal hamsters at least.

The stroma is an important constituent for the zoning, because the characteristic arrangement of the cells in each zone seems to be related to the stroma with the blood vessels. In the present study azan-, PAS-staining or Gomori's silver impregnation were employed for demonstration of the interstitial connective tissue. Particularly the PAS-technique is most available for the present purpose, because this stain can demonstrate even relatively fine fibres positively, as stated by Clara (1952). In the adrenal of the hamster Knigge (1954a) noted that a layer of connective tissue at the cortico-medullary boundary increases in thickness with age, and that the connective tissue intervening between the cortex and medulla is sparse in the male. According to the obseavations reported in this paper, no particular layer of fibrous tissue is present around the medulla in both sexes uutil 50 days of age. Later the interstitial connective tissue in the zona reticularis increases gradually with advancing age. Especially in females the stroma becomes remarkably increased with the decrease of the cortical cells of this zone, and a fibrous band appears between the cortex and medulla. In males the connective tissue is sparse, although it appears in considerable amounts after 160 days of age. The presence of fibrous layer as seen in females is rare in males. In adult hamsters the stroma of the reticularis contains pigmented cells of phagocytic nature in greater or less amounts as in the guinea pig (Ito, 1952). These pigmented cells are readily distinguished from the pigmented cortical cells in many respects. Firstly, they make their first appearance between 75 and 90 days of age in males and at 100 days in females; namely, they appear earlier than the cortical pigmented cells which first appear at 200 days. Secondly, as a matter of course, the pigmented cells under consideration, which are present within the stroma, are different in location from the cortical cells with pigment. Thirdly, the morphological characteristics are definitely dif- 
ferent in both types of cells; the stromal pigment cells are far smaller than the cortical cells, and their pigment generally occurs in the furm of larger or smaller masses.

\section{F) Germinal layer}

Where the germinal layer lies in the cortex has long been disputed. As to this problem, there is no agreement in the literature; various regions such as the glomerulosa, fasciculata, transitional zone, or both the glomerulosa and fasciculata have been enumerated as the germinal layer of the cortex by many authors in various animals. Furthermore, in recent years, as already stated, increasing numbers of investigators, based on the theory of the capsular or subcapsular origin of the cortical cells, have considered the capsular or subcapsular region to be a germinal layer of the cortex. Recently, on the basis of an extensive review of the literature, Bachmann (1954) stated that the mitotic activity of the cortical cells is different in different species and probably in different strains even of the same species, and further that it is very subject to various influences. Therefore, disagreement in the results of former studies concerning this problem may be attributed in part to these reasons. In the hamster, mitotic figures are present in the cortical cells with no particular local concentration during the juvenile stages. After the cortex has differentiated into its characteristic three zones, the mitotic activity occurs in the glomerulosa and fasciculata. The mitoses, of course, occur frequently in the actively growing cortex, but, after the cortex has attained its adult state, the mitotic activity declines gradually. The activity is present for a long time at least up to 180 days of age. From the present data (table 2), however, a special zone cannot be regarded as a germinal layer.

\section{Summary}

1. Adrenal cortices of golden hamsters ranging from birth to 300 days of age of both sexes were histologically studied.

2. The usual zoning can be applied to the cortex of this animal as is done in other common laboratory rodents.

3. The zona glomerulosa becomes differentiated from the outer zone which occupies the periphery of the cortex at and shortly after birth. At about 15 days of age the detailed structure of the glomerulosa reaches the definite condition. The cytological details of the glomerulosa cells suggest that these cells are well-differentiated and 
probably possess secretory activity. The transitional zone, though thin, is sometimes present between the glomerulosa and fasciculata, and its cells are lèss differentiated in appearance.

4. The zona fasciculata shows a fascicular arrangement after 18 to 20 days of age and attains the mature state in details of cell structure at the age of 25 to 30 days. The fasciculata cells lack lipoid vacuoles characteristic of those of other species. The spherical bodies, liposomes, which are distributed among the mitochondria, are regarded as cytoplasmic structures morphologically and probably functionally essential to the cells of this zone. In adults cellular degeneration, though to relatively slight degree, occurs in the fasciculata in both sexes; in males the degenerative cells appear as cells with large vacuoles mostly in the innermost portion of the zone from 65 to 75 days on, and in females they occur singly scattered throughout the zone after 45 days of age. In hamsters older than 200 days the fasciculata cells of ten contain yellow to brown pigment in small amounts.

5. The zona reticularis becomes apparent at 30 days of age in both sexes. This zone presents a remarkable sex difference not only in thickness but also in structure. Particularly the male reticularis is well-developed, and its cytological structure may suggest some functional activity of this zone. Pigment which is a normal product of old age occurs in this zone after 200 days.

6. The capsule of the adrenal gland acquires the almost definite structure at about 30 days. Even in adults the capsular or subcapsular tissues occasionally remain sparsely fibrous in some few places, but the transformation of fibroblasts into glomerulosa cells cannot be confirmed under normal conditions. The stromal connective tissue in the zona reticularis tends to increase with advancing age after 50 days of age. Particularly in adult females a fibrous band appears between the cortex and medulla, whereas in males its appearance is generally rare. The pigment cells of phagocytic nature occur in greater or less amounts in the stroma of the reticularis after 75 to 95 days in males and after 100 days in females.

7. Mitotic figures are present with no particular local concentration in the cortex of young hamsters, but they are confined to the glomerulosa and fasciculata after the establishment of the three cortical zones. After the cortex has attained its adult state, the mitotic activity. declines gradually and is present long at least up to 180 days of age. In the hamster, however, a special zone cannot be regarded as germinal layer of the cortex. 
I am greatly indebted to Prof. Ch. Togari for his constant encouragement and valuable criticisms. This study was supported by a research grant from the Department of Education.

\section{References}

Alpert, M. 1950 Observations on the histophysiology of the adrenal gland of the golden hamster. Endocrinology, 46: 166-176.

Ando, T. 1953 Histological studies on the secretory process of the adrenocortical cells (Japanese). Clin. Endocrin., 1: 218-230.

Bachmann, R. 1939 Zur Frage der Zona germinativa der Nebennierenrinde. Klin. Wochenschr., 18: 783-784.

1953 Veränderungen der Nebennierenrinde des Hundes bei akuter und chronischer Kreislaufbelastung. Z. Zellforsch., 38: 1-25.

1954 Die Nebenniere. In Handbuch der mikroskopischen Anatomie des Menschen (Möllendorff-Bargmann) Bd. 6, T1. 5, Springer-Verlag, Berlin • Göttingen • Heidelberg.

Cater, D. B. and J. D. Lever 1954 The zona intermedia of the adrenal cortex. A correlation of possible functional significance with development, morphology and histochemistry. J. Anat., 88: 437-454.

Clara, M. 1952 Beiträge zur Kenntnis der Gitterfasern. Z. Zellforsch., 37: 389-405.

Dallwig, R. 1954 Mitoseaktivität und Kerngrössen in der Nebennierenrinde der Ratte nach Dursteinwirkung. Z. mikrosk.-anat. Forsch., 61: 138-154.

Deane, H.W. and R.O. Greep 1946 A morphological and histochemical study of the rat's adrenal cortex after hypophysectomy, with comments on the liver. Am. J. Anat., 79: 117-146 (cited from Bachmann, 1954).

Deane, H.W., J.H. Shaw and R.O. Greep 1948 The effect of altered sodium or potassium intake on the width and cytochemistry of the zona glomerulosa of the rat's adrenal cortex. Eodocrinology, 43: 133-153.

Ehrenbrand, F. 1954 Beiträge zur Morphokinese der Nebennierenrinde bei experimenteller Hyperthyreose. Anat. Anz., 101: 41-63.

Frazão, J.V. 1952 La méthode de Mac-Manus pour la recherche des glycoprotéines dans l'étude cytologique de la glande surrénale. C. r. Soc. Biol. Paris, 146: 958 960 (cited from Bachmann, 1954).

Greep, R.O. and H.W. Deane 1949 The cytology and cytochemistry of the adrenal cortex. Ann. New York Acad. Sci. 50, Art. 6: 596-615.

Holmes, W.N. 1955 Histological variations in the adrenal cortex of the golden hamster with special reference to the $\mathrm{X}$ zone. Anat. Rec., 122 : 271-287.

It o, T. 1952 Histology and histogenesis of the adrenal cortex in the guinea pig. Folia anat. jap., 24: 269-289.

Jayne, E.P. 1953 Cytology of the adrenal gland of the rat at different ages. Anat. Rec., 115 : 459-475.

Keyes, P.H. 1949 Adrenal-cortical changes in Syrian hamsters following gonadectomy. Endocrinology, 44: 274-277 (cited from Bachmann, 1954).

Knigge, K.M. 1954a The effect of hypophysectomy on the adrenal gland of the hamster (Mesocricetus Auratus). Am. J. Anat., 94: 225-262.

$1954 \mathrm{~b}$ The effect of acute starvation on the adrenal cortex of the hamster. 
Anat. Rec., 120: 555-575.

Koneff, A.A., M.E. Simpson and H.M. Evans 1946 Effects of chronic administration of diethylstilbestrol on the pituitary and other endocrine organs of hamsters. Anat. Rec., 94 : 169-191 (cited from Bachmann, 1954, and others).

Lavelle, F.W. 1948 Effects of castration in young postnatal hamsters. Anat. Rec., 100: 750 (cited from Bachmann, 1954, and others).

Mitchell, R. M. 1948 Histological changes and mitotic activity in the rat adrenal during postnatal development. Anat. Rec.. 101: 161-181.

Mori, S, and T. Ando 1955 Morphological studies on the adrenocortical function (Japanese). Transaction of the Conference on Endocrinology, 7: 1-40.

Ortiz, E. 1953 The effects of castration on the reproductive system of the golden hamster. Anat. Rec., 117: 65 -87.

Peczenik, O. 1944 Action of sex hormones on the adrenal cortex of the golden hamster. Proc. Roy. Soc. Edin., B, 62: 59-65 (cited from Bachmann, 1954, and others).

R og of f, J. M. 1932 The suprarenal bodies. In Cowdry's Special Cytology, 2. edit., vol. 2, Paul B. Hoeber, New York.

Tonutti, E. 1941 Hormonal gesteuerte Transformationsfelder in der Nebennierenrinde? Z. mikrosk--anat. Forsch., 50: 495-501 (cited from Bachmann, 1954). 1942a Zur Histologie der Nebennierenrinde: Bau und Histochemie bei der Atrophie des Organes nach Hypophysektomie. Z. mikrosk.-anat. Forsch., 51 : 346-392 (cited from Bachmann, 1954).

1942b Die Umbauvorgänge in den Transformationsfeldern der Nebenniernrinde als Grundlage der Beurteilung der Nebennierenrindenarbeit. Z. mikrosk-anat. Forsch, 52: 32-86 (cited from Bachmann, 1954).

Wexler, B.C. 1951 Effect of a single injection of diethylstilbestrol on the adrenal cortex in the golden hamster. Endocrinology, 49:36-44.

Yoshimura, F. 1954 Etude cytologique sur la corticosurrénale à l'hyper- et à l'hypofonction chez le rat. Endocrinol. Japon., 1: 177-188.

Zwemer, R.L., R.M. Wotton and M. G. Norkus 1938 A study of corticoadrenal gland cells. Anat. Rec., 72: 249-263.

\section{Explanation of Plates}

Adrenals for figures 1 to 6 were fixed in Bouin's fluid, sectioned at $5 \mu$ and stained with Mayer's hematoxylin and eosin. Adrenals for figures 7 to 11 were fixed in Zenkerformol, sectioned at $4 \mu$ and stained with Heidenhain's iron hematoxylin.

\section{Plate 1}

1. Adrenal of a 4-day-old female hamster. From above downwards are noted: the capsule, the outer zone, the inner zone. Most cells of the outer zone are increased in cell and nuclear size. $\times 350$

2. Adrenal of a 15-day-old male hamster. The zona glomerulosa is discerned peripherally. The remainder is not clearly defined into zones. $\times 170$.

3. Adrenal of a 30-day-old male hamster. The reticularis (below) has appeared. With this magnification the reticularis may hardly be demarcated from the fasciculata. $\times 170$.

4. Adrenal of a 30-day-old female hamster. The innermost zone (below) is the reticularis, which appears as a thin layer composed of small cells closely packed. $\quad \times 170$.

5. Adrenal of a 35-day-old male hamster. Same as fig. $3 . \times 170$. 
6. Adrenal of a 35-day-old female hamster. The perimedullary layer is the zona reticularis, which exhibits a remarkable sexual difference in thickness and appearance. $\times 170$.

\section{Plate 2}

7. Adrenal of a female hamster immediately after birth. The cells of the outer zone are filled with granular and short rod-like mitochondria. $\times 1700$.

8. Adrenal of a female hamster immediately after birth. The cells of the inner zone contain numerous rod-like and granular mitochondria. $\times 1700$.

9. Adrenal of a 13-day-old female hamster. The cells of the outer zone (zona glomerulosa) have minute vacuoles. $\times 1700$.

10. Adrenal of a 30-day-old female hamster. The cells of the fasciculata contain numerous granular mitochondria and small spherical bodies (liposomes). $\times 1700$.

11. Adrenal of a 40-day-old male hamster. The reticularis cells are filled with large spherical bodies. $\times 1700$. 
Plate I

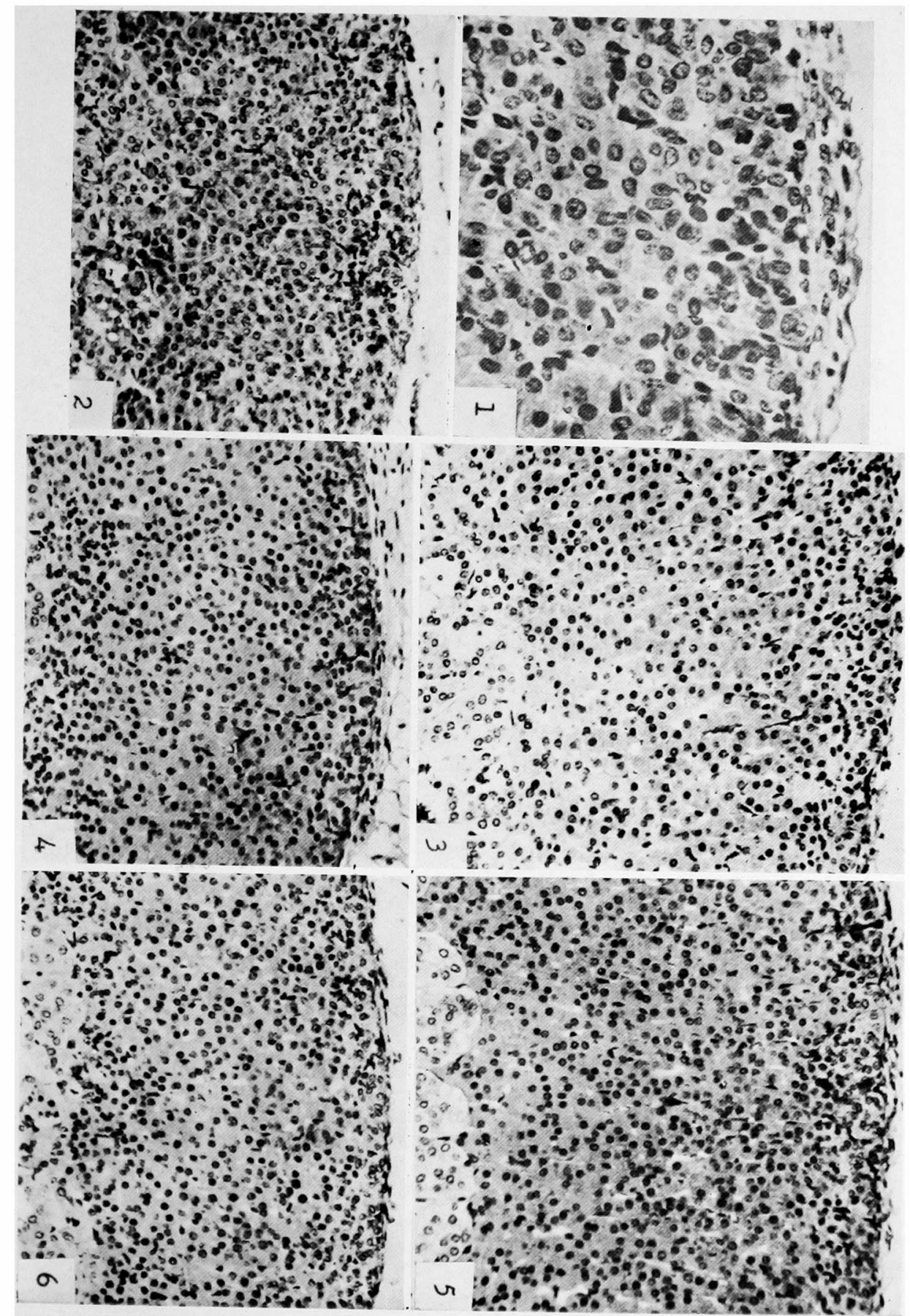

T. Ito 
Plate II

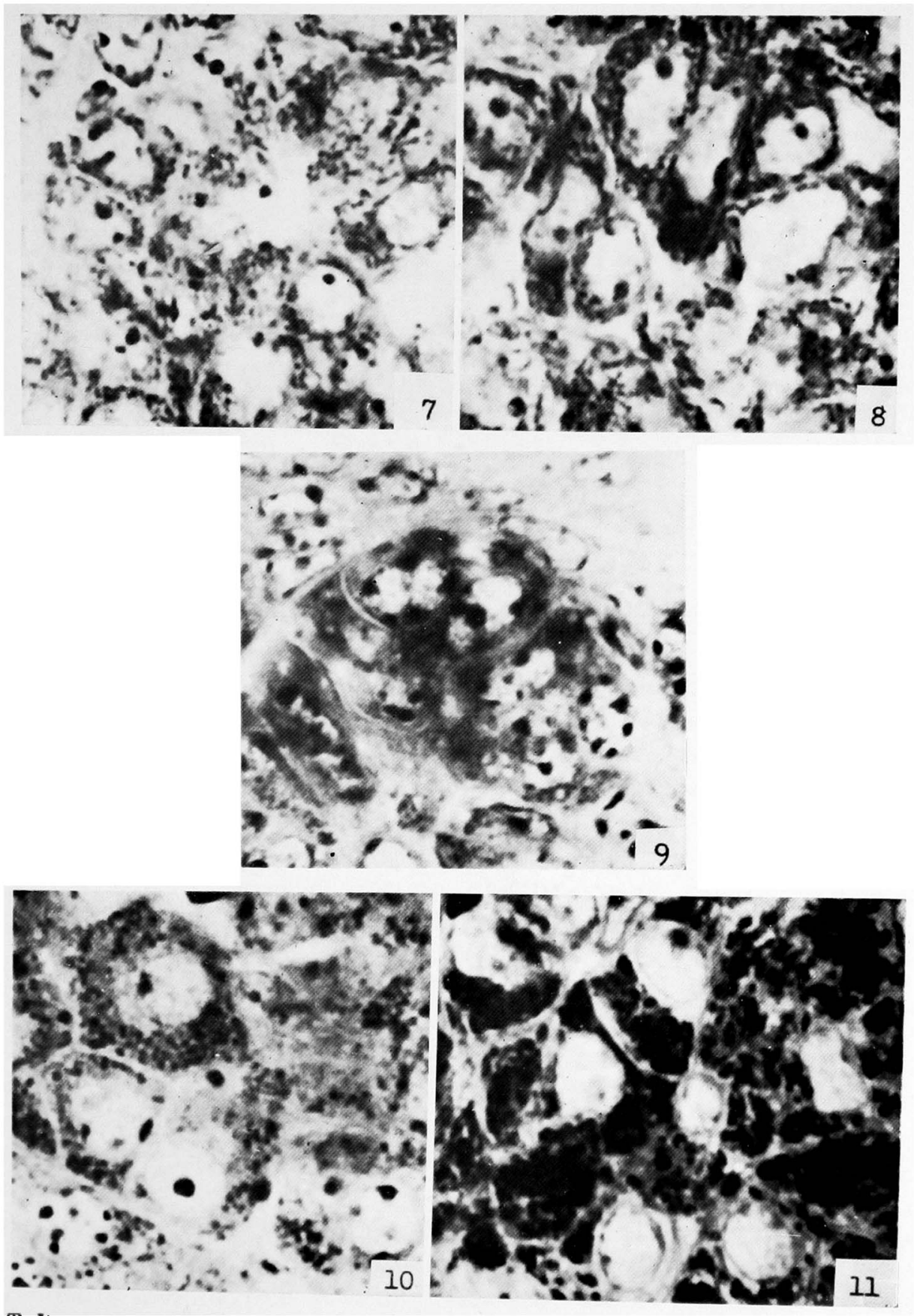

T. Ito 